\section{A CASE OF CORNET PLAYER'S CRAMP.}

\section{BY WILLIAM ALDREN TURNER, M.D., M.R.C.P. LOND.}

THE list of occupation-neuroses (Beschäftigungs-Neurosen) does not include, so far as I can ascertain, an instance of the condition illustrated by the following case, nor is the patient himself aware of the occurrence of a like affection amongst his professional brethren:-A man aged twenty-nine has played the cornet as a means of livelihood since he was nine years of age. For ten years he was in the band of the Coldstream Guards, but for the last few years he has devoted himself to orchestra and solo playing. About two years ago he noticed that he was unable to sound certain notes from an inability to direct the movements of his tongue for that purpose. This condition has remained more or less constant until the present time. The patient gires a highly intelligent account of his condition, which is as follows: $\mathrm{He}$ is unable to make certain movements of the tongue which are essential for the acts known as "single, double and triple tonguing," and which may be graphically represented by the signs "tŭ ", "tŭ kŭ ;" " tŭ tŭ kŭ" respectively. This movement is readily imitated by imagining a hair on the tip of the tongue which one is endeavouring to remove by inserting the point of the tongue between the lips and blowing. An interesting feature in connexion with the case is that he can perform these movements readily and easily in his own room when practising or when allowed his own time, but he cannot do so when suddenly called upon by the conductor's bâton. He has also noticed that after playing for some time the condition of his tongue improves instead of becoming worse. In all other actions, both in playing the cornet and otherwise, the movements of the tongue are perfectly good. At no time was there any pain in it. Physical examination showed that the tongue was large, atonic and somewhat indented at the margin by the teeth, but this condition improved very much under the influence of strychnia and dilute hydrochloric acid. There were a few fibrillary tremors towards the point. The tongue reacted normally to galvanism and faradaism. There was no affection of the lips or soft palate, and the linguals and labials were well formed. Both knee-jerks were equal and of normal force. The patient has always had good health; he is a non-smoker and temperate. There is no known history of any neurosis in the family. He is unable to ascribe any exciting cause for the affection except that at its outset he was in feeble health after a somewhat severe attack of influenza and was at the same time busily engaged in his professional work.

The only movements of the tongue which are implicated in this case are those essential for the production of certain (staccato) notes upon the cornet, hunting-horn, or other wind instrument; these movements have been acquired, and they are the most complex which the players upon wind instruzents require to produce. In other words, certain cell-groups subserving the movements of the tongue have been educated by practice for the perfecting of certain actions, all the other more natural movements of the tongue being unimpaired. It has been pointed out that if in the occupation-neuroses the affected movements are fine (e.g., in writers, pianists, telegraphists \&c.) these special movements only are implicated, whilst if the movements are coarse (as in hammermen, treadlers \&c.) other actions than that of the occupation are impaired. For example, the patient suffering from writer's cramp can, as a rule, readily work the typewriter or play the piano, or, as Dr. Poore ${ }^{1}$ has shown, even write with a pencil ; but the sufferer from treadler's cramp has great difficulty in going upstairs. ${ }^{2}$ The probable explanation of this is to be found in the fact that the fine movements required in writing, piano-playing sc. are complex and special movements only acquired by education and practice, whilst the coarse movements of the hammerman and the treadler, although used by them in an exaggerated and altogether abnormal way, are those which are normally and daily performed in the ordinary habits of iife. Hence one has to look for the cause of the occupationcramps in fatigue, nutritive impairment, or even temporary paralysis of cell groups : either those which, having been specially educated for a particular action, are thereby more prone to fatigue, or those which, regulating certain normal movements, have been worked to excess. In the case directly

2 Medical and Chirurgical Transactions, vol. Ixi.

2 Rivers: Brain, vol. xiv., p. 110. under discussion fatigue has probably caused the defective action of the cells regulating the special movements, as there was no alteration in the electrical reactions of the lingual muscles; that an organic alteration in the nerve cells may occasionally occur in the occupation-cramps is apparent from the decided electrical alterations which have been observed in well-recorded cases. I am indebted to Dr. Ferrier for the opportunity of studying this case.

Queen Anne-street, $\mathbf{W}$.

\section{Climical 影otes:}

\section{MEDICAL, SURGICAL, OBSTETRICAL AND} THERAPEUTICAL.

\section{ENTERIC FEVER $v$. SIMPLE CONTINUED FEVER :} A Question of Nomenclature.

BY SURGEON-CAPTAIN H D. ROWAN, ARMY MEDICAI. STAFF.

IN the course of Dr. J. Mackie's observations on the prevalence of typhoid fever amongst British soldiers in garrison in Egypt he states his belief that "simple continued fever is, in general, a mild, non-fatal form of typhoid fever, and probably the precursor of a severer form to follow." 1 Such a statement as this raises a question of nomenclature the settlement of which is of the highes: importance for the study of enteric fever. Until we can differentiate between simple continued fever and enteric fever the statistics on the prevalence and mortality of the latter disease are practically worthless. Possibly many of the cases of simple continued fever might be relegated to the category of enteric fever; but there would, I think, still remain the large majority of cases which have no such causation, but are due to the effects of heat. This, I think, is the only admissible interpretation of the epidemic which occurred at Ferozepore in the Punjaub in 1889 , to which the following table refers:

April. May. Jane. July. Total.

Simple continued ferer $\quad . .52 \quad \begin{array}{lllllll} & 52 & 11 & \ldots & 105 & \ldots & 82\end{array}=250$

Enteric fever .. ... ..

Heat apoplexy .. $. . \quad \ldots \quad-\ldots-\ldots 17 \ldots-17$

Such a sequence of events is not uncommon. I have selected this epidemic because it is one that came under my personal notice. The following features were common to all the 250 consecutive cases of simple continued fever, and they are, I think, sufficiently distinctive to prevent confusion between it and enteric fever: (1) Simple continued fever was most prevalent in June and July (after, not preceding, enteric fever); (2) it was associated with excessive heat (note the occurrence of heat apoplexy); (3) the average age of the patients was twenty-seven years; (4) the average Indian service is two years and three-twelfths; (5) the average duration in hospital was nine days; (6) the symptoms were fever (from one to three days), headache, irsomnia, dilatation of pupils, frequent micturition \&c.; and (7) the mortality was nil. I do not know whether these are the invariable characteristics of simple continued fever. I have enumerated them because they help to define what is not uncommonly meant by the term, and if any further vitiation of statistics is to be prevented some such definition of simple continued fever (more appropriately called "thermic fever") is indispensable.

Bradford.

\section{SMALL-POX IN THE VACCINATED AND THE UNVACCINATED.}

By N. S. Mannifg, F.R.C.S. IReL.,

MEDiCal SUPERINTENDENT, CITY HOSPITAL, BIRMINGHAM.

The following notes may probably be of some interest as the cases are typical examples of what constantly occurs in the treatment of small-pox :-

CASE 1.-A girl aged eleven years. She was vaccinated in infancy ; there were four scars; the area was 1.07 square inch, being shallow and badly foreated. The patient was 
admitted to the City Hospital, Birmingham, on March 21st, 1893. The eruption consisted of a few papules on the face and forearms, which never developed into true vesicles. She had no symptoms whatever after the appearance of the eruption.

CASE 2.-A boy aged three years and a half. He had not been vaccinated, The patient was admitted to the hospital on March 22nd. The eruption was confluent. He died after great suffering on March 31st. The photograph, of which the engraving is a copy, was taken on March 28th,

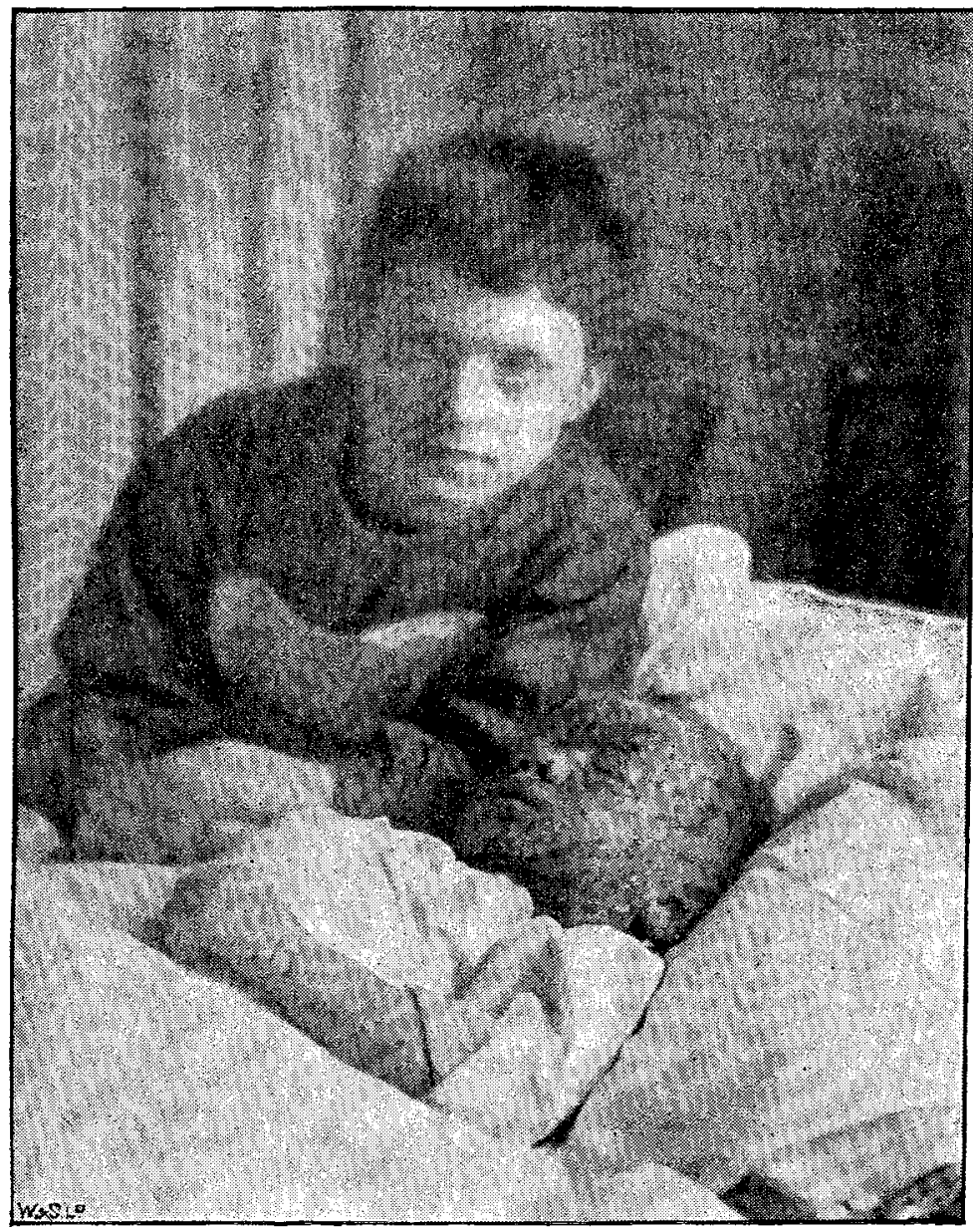

being the thirteenth day of the disease in Case 1 and the tenth day in that of Case 2. The patients, who were sister and brother, contracted the disease from the same source and were subjected to the same surroundings and influences in every particular except that the girl had had an attack of scarlet fever some months previously, from which she was just convalescent.

Birmingham.

\section{GENERAL EMPHYSEMA AS A RESULT OF} PULMONARY TUBERCLE.

BY J. Reginald Fuller, M.R.C.S., L.R.C.P., L.S.A. LoNd, SENIOR RESIDEN'T MEDICAL OFFICER TO THE CHILDREN'S HOSPITAL, BIRMINGHAM.

A CHILD aged four years was admitted to the Children's Hospital on March 14th, 1893, suffering from pulmonary tuberculosis. The family history showed a tuberculous tendency. The present illness had commenced fifteen weeks previously with gradual wasting, cough, sweating and the ordinary signs of tubercle. There was no whooping-cough or any other disease that would cause the child to strain. On admission the patient was much emaciated, and was affected with a constant dry hacking cough and night sweats; but there was no hæmoptysis. On examination there were hurried respiration, impaired resonance at the apices of both lungs and over both backs ; and marked tubular breathing at the back, with moist sounds, and vocal resonance was apparently increased. On March 18th emphysema appeared suddenly, at first in the upper part of the back and neck; thence it spread rapidly to the face, eyelids and forehead, completely closing the eyes, and downwards along the whole trunk to the scrotum, bounded on each side by Poupart's ligament and behind by the rim of the pelvis. The time from the first appearance of the swelling to its full development was under two hours. The whole appearance of the child was altered; he appeared to be nearly twice his previous size. The eyes were quite closed. The swellings about the body were more marked in the flanks and scrotum. Pricking the swellings was followed by re-distension in a very short time. The patient suffered much from dyspnœa ano the cough was very troublesome ; there was no apparent impulse in the swellings upon coughing. The child appeared to. rally somewhat from the shock after stimulation, but after the first night he gradually sank and died on the 21st (three. days after the emphysema commenced), the dyspnoea increas. ing considerably towards the end. The temperature remained normal throughout after the first shock, at which time it fell to $97^{\circ}$. At the necropsy, held on the following morning, the body was found to be almost destitute of subcutaneous fat, though the skin was separated two inches or more in places by the extravasated air from the deeper structures. On opening the chest no fluid was found in the pleural cavities; both lungs were slightly adherent to the parietes, more so behind than in front, but neitherlung was much collapsed. The mediastinal glands were enlarged, caseous, and breaking down. Botb apices were almost solid with tuberculous masses, and miliary tubercles were scattered throughout both lungs. The left upper lobe was found to be partly adherent to one large gland, which was in turn fixed to the parietes; this gland was broken down in the centre, and a probe could be passed through it into the cellular tissue. No cavity in the lung could be discovered, though the communication was doubtless established by the ulceration and breaking down of the cells at the situation of this gland.

Birmingham.

\section{DISLOCATION OF THE HIP IN A CHILD THREE YEARS OF AGE.}

By Surgeon-Major D. Charles Dafidson, I.M.S., CIVIL SURGEON, SATARA, INDIA.

A Hindoo cHILD about three years of age was brought to the Civil Hospital, Satara, on March 31st last with a deformity of the hip. The history was obscure. It was stated that the child whilst playing fell down on a stone and sustained the injury for which he was brought to the hospital, but nothing very clear or definite could be elicited. This was said to have occurred more than a fortnight previously to admission. On a careful examination he was founc to be suffering from dislocation of the right hip-joint of the ilio-sciatic type. The child was placed under chloroform and the dislocation was reduced by manipulation with some little difficulty.

Remarks. - The chief feature of interest in this case is the great rarity of dislocation of the hip-joint in young children.

\section{TERTIAN AGUE OCCURRING DURING AN ATTACK OF ENTERIC FEVER.}

BY T. SYDNEY SHORT, M.D. LOND.

IT is always interesting to note occasions when two maladies attack the human frame at the same time and to watch the result that accrues. The following case illustrates an attack of tertian ague occurring during the course of enteric fever.

The patient, a healthy young man aged twenty-nine, hac formerly been in the army in India and had suffered on two occasions from ague when there. Since his return to England four years ago he had been quite free from it. During the third week of what appeared to be in all respects a typical attack of enteric fever he had a rigor, with the temperature rising to $104^{\circ}$, followed by profuse sweating and a rapid fall of the temperature to $95.2^{\circ}$, as taken in the rectum. This naturally gave rise to alarm, but he himself said with a calmness that was reassuring, "It's only an attack of the ague " I had it four years ago in India." The temperature rose again the next day without any rigor, but the day after he had another rigor, the temperature reaching nearly $105^{\circ}$, followed by a fall to $95 \cdot 6^{\circ}$. Quinine had been exhibited and 